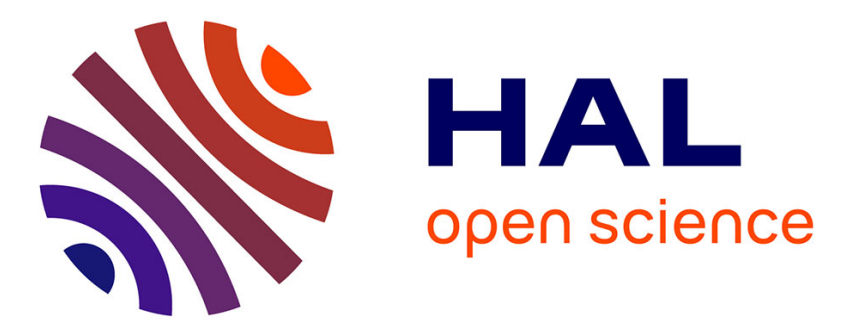

\title{
Effect of a 6-month brisk walking program on walking endurance in sedentary and physically deconditioned women aged 60 or older: A randomized trial
}

H. Blain, A. Jaussent, M.-C. Picot, Laurent Maïmoun, O. Coste, T. Masud, J. Bousquet, P. Bernard

\section{To cite this version:}

H. Blain, A. Jaussent, M.-C. Picot, Laurent Maïmoun, O. Coste, et al.. Effect of a 6-month brisk walking program on walking endurance in sedentary and physically deconditioned women aged 60 or older: A randomized trial. Journal of Nutrition, Health \& Aging, 2017, 21 (10), pp.1183 - 1189. 10.1007/s12603-017-0955-7 . hal-01740250

\author{
HAL Id: hal-01740250 \\ https://hal.science/hal-01740250
}

Submitted on 12 Dec 2019

HAL is a multi-disciplinary open access archive for the deposit and dissemination of scientific research documents, whether they are published or not. The documents may come from teaching and research institutions in France or abroad, or from public or private research centers.
L'archive ouverte pluridisciplinaire HAL, est destinée au dépôt et à la diffusion de documents scientifiques de niveau recherche, publiés ou non, émanant des établissements d'enseignement et de recherche français ou étrangers, des laboratoires publics ou privés. 


\title{
EFFECT OF A 6-MONTH BRISK WALKING PROGRAM ON WALKING ENDURANCE IN SEDENTARY AND PHYSICALLY DECONDITIONED WOMEN AGED 60 OR OLDER: A RANDOMIZED TRIAL
}

\author{
H. BLAIN, A. JAUSSENT, M.-C. PICOT, L. MAIMOUN, O. COSTE, T. MASUD, J. BOUSQUET, \\ P.L. BERNARD
}

PLEASE ADD AFFILIATION AUTHOR; Corresponding author: H. Blain, Centre de Prévention et de Traitement des Maladies du Vieillissement Antonin Balmès, Centre Hospitalier Universitaire de Montpellier, Montpellier, France, h-blain@chu-montpellier.fr

\begin{abstract}
Background: Walking endurance is a predictor of healthy ageing. Objective: To examine if a 6-month brisk walking program can increase walking endurance in sedentary and physically deconditioned older women. Trial design: Randomized controlled trial. Setting: Women recruited from public meetings aimed at promoting physical activity in women aged 60 or older. Subjects: 121 women aged $65.7 \pm 4.3$ years, with sedentary lifestyle (Physical Activity Questionnaire for the Elderly score <9.4), and a 6-minute walking distance (6MWD) below normal value based on their gender, age, and body weight, and weight. Methods: Women were randomly assigned to a $150 \mathrm{~min} /$ week brisk walking program (two supervised sessions and one session on their own per week) for six months (exercisers) $(n=61)$ or a control group with physical activity allowed freely $(n=60)$. Outcome: The primary outcome was relative change in 6MWD. Results: 54/61 exercisers and 55/60 control subjects completed the program and data analysis was possible for 51 exercisers and 47 controls. At baseline, 6MWD was on average $23.1 \%$ and $22.5 \%$ below age-matched norms in exercisers and controls, respectively. Attendance rate for supervised sessions was $92 \%$ in exercisers. The 6MWD increased more significantly in exercisers than in controls (mean increase of $41.5 \%$ vs $11.0 \%$; $<<0.0001$ ). Over the 6-month program, 38 exercisers $(74.5 \%)$ vs 5 controls $(10.6 \%)$ had a 6MWD over the age-matched norm $(\mathrm{p}<0.0001)$. Exercisers with the highest tertile of 6MWD improvement $(>46 \%)$ were those with baseline lowest values of 6MWD $(\mathrm{p}=0.001)$ and highest values of body mass index $(\mathrm{BMI})(\mathrm{p}<0.01)$. Conclusion: Present results support recommendation that brisk walking programs should be encouraged to improve walking endurance in physically deconditioned women aged 60 or older, especially in those with high BMI.
\end{abstract}

Key words: Walking endurance, brisk walking, muscle strength, women, ageing.

\section{Introduction}

Low walking endurance is associated with cardiovascular morbidity, low functional status, and dependence in older women $(1,2)$. Physical activity guidelines recommend that adults should exercise with moderate-intensity aerobic physical activity to improve their exercise endurance and prevent chronic diseases (3). Unfortunately, more than two third of postmenopausal women engage in less physical activity than recommended $(4,5)$.

Brisk walking is the main example of moderate-intensity activity recommended in guidelines (3). Brisk walking in particular may be a convenient activity to circumvent barriers to exercise in older adults since it can be performed in the individual's proximity zone, it requires minimal formal training and equipment, and it can be performed at a variety of intensities, either alone or in a group.

Brisk walking interventions seem to elicit only a small beneficial effect on exercise endurance in adults in whom intensity, adherence, and duration of the training program is low, such as in obese subjects, in those with chronic diseases, and in women with high attrition rates due to overuse injuries (6-10). Few randomized studies have evaluated the effects of brisk walking programs on walking endurance in sedentary and physically deconditioned women aged 60 years or over, and participants characteristics that may influence effectiveness of brisk walking programs in this subgroup of subjects are not well known (11).

We conducted a randomised controlled trial to examine the effect and the predictors of effectiveness on walking endurance of a 6-month brisk walking program in women aged 60 years or older with documented sedentary lifestyle and physical deconditioning.

\section{Methods}

\section{Ethics and approval}

This single blind cluster randomised-controlled trial (registered with ClinicalTrials.gov, number NCT02094144) led as part of the MACVIA program in Languedoc-Roussillon (reference site of the European Innovation Partnership on Active and Healthy Ageing) was approved by the Committee for Protection of Human Subjects (CPP Sud-Méditerranée III, Number: 2008.07.04) and granted by the French Federation of Physical Education and Voluntary Gymnastic (FFEPGV), a government funded exercise group, by the French Ministry of Health, and the University hospital of Montpellier (France). All study participants provided written informed consent. 


\section{Participants}

The full protocol for the trial has been reported previously (12-15). Participants were recruited in 2013-2014 via advertisements published in newspapers. Recruitment advertisements included the purpose of the study, age and gender restrictions (women aged 60 years or older), and the fact that the intervention was provided at no cost to participants. Women interested by the study were invited to attend meetings aimed at promoting physical activity and to get additional information regarding the design of the study, qualifications for eligibility, benefits, time commitment, IRB protocol number, and approval details. Women were enrolled in the study if they had no incapacitating chronic disease or contraindications to exercise, according to their physician's opinion, a body mass index $(B M I) \leq 30 \mathrm{~kg} / \mathrm{m}^{2}$, if they had a sedentary lifestyle [Physical Activity Questionnaire for the Elderly (PAQE) score $<9.4$ ] (16) and they were physically deconditioned [if their 6-minute walking distance (6MWD) was below a normal value, calculated based on their gender, age, and body weight, and weight] (17).

\section{Sample size}

According to the study of Enright et al., the mean 6-min walk distance (6MWD) in a population of 2,281 adults $\geq 68$ years old was $344 \pm 88 \mathrm{~m}$ (18). Based on the results of previous randomized controlled trials (11), we estimated an expected improvement in the exercise group of $15 \%$ when compared to control group. To detect a difference between groups of $51.6 \pm 88 \mathrm{~m}$, a power of $80 \%$ and an alpha error of $5 \%$ under a bilateral hypothesis (2-sided test), the sample size required was 47 subjects by group. The rate of lost to follow-up was estimated to $5 \%$. The estimated number of participants to include in the study was 50 in each group.

\section{Interventions}

The exercise intervention consisted of 50 minutes of moderate-intensity exercise three days per week for six months. Subjects attended two sessions per week at 2 p.m., supervised by a trained exercise leader of the FFEPGV, in groups of 10 to 12 , and one session per week on their own, with the same program as the previous supervised session, performed at the most convenient moment for each participant. The walking training, conducted in a city park, began with a target of $40 \%$ of maximal heart rate and gradually increased to a target of $60 \%$ to $80 \%$ of maximal heart rate, at which point it was maintained for the duration of the study. The maximal heart rate was calculated using Tanaka's equation [208 - $(0.7 \mathrm{x}$ age $)]$.

Participants wore heart rate monitors (Polar Electro Inc, Woodbury, NY) during all supervised and unsupervised exercise sessions. Distance walked, duration, and mean heart rate were recorded during supervised sessions only. Physical activity was allowed freely in women randomly assigned to the control group. During the study, exercisers and control participants were asked to maintain their usual diet without any measurement of food intake during the program.

\section{Outcomes}

The primary outcome was change in 6MWD in exercisers and controls. We assessed the 6MWD at baseline and after 6 months, according to a previously published protocol (12-15, 19). Women wearing comfortable clothes and shoes were asked to walk back and forth as far as possible for 6 minutes on a flat and hard surface in a 30 -meter hallway. The turnaround point was indicated with a cone and the starting line, corresponding to the beginning and the end of each 60-meter lap, was marked on the floor using brightly coloured tape.

The following parameters were measured in both intervention and control groups at baseline and after 6 months: 1) Body height using a stadiometer; 2) Body weight using a balance-beam scale [Coefficients of variation $(\mathrm{CV})$ of replicate measures of height and weight of $0.3 \%$ and $0.05 \%$, respectively]; 3) Total lean body mass (excluding bone mineral content) and fat mass, using DXA (Hologic QDR-4500A, Hologic, Inc., Waltham, MA)(CV $<3 \%$ for whole body fat and lean mass); 4) Maximum grip strength using the JAMAR dynamometer (Smith and Nephew, Memphis, TN) $(\mathrm{CV}<10 \%)$; 5) Physical activity by using the French version of the PAQE [16]; 5) Exercisers were questioned at the beginning and end of every supervised session regarding possible adverse effects of the program. All measurements were performed by a technician blinded to the participants' group randomization.

\section{Randomization}

Eligible patients were randomly assigned with a ratio 1:1 to intervention or control groups. The randomization list was computed in random-size blocks using Statistical Analysis System (SAS) software and group assignment was placed in a sealed envelope which was opened by the study coordinator at the time of randomization.

\section{Statistical Analyses}

Intervention and control groups were described using frequencies and percentages for categorical variables and means and standard deviation (SD) for quantitative variables.

The main and secondary outcomes, corresponding to relative variation over the 6 -months program [(value after 6-month follow-up - baseline value)/ baseline value) x100] were assessed using Student or Mann-Whitney test according to data distribution. A sensitivity analysis was performed for the main outcome, replacing missing data for 6MWD relative variation by 0 . All analyses were performed in an intent-to-treat basis. To identify characteristics of subjects with the highest improvement in $6 \mathrm{MWD}$, the exercisers belonging to the upper tertile of 6MWD improvement ( $\geq 46.3 \%$ ) were compared to the other participants using logistic regression models. Significance was set at $\mathrm{p}<0.05$. All analyses were performed with Statistical Analysis System (SAS) Enterprise Guide, version 4.3 (SAS Institute, Cary, NC, USA). 


\section{Results}

\section{Participants flow}

Among 580 women encountered during the public meetings, 219 women met the inclusion criteria and 121 agreed to participate in the study. Women were then randomized between exercise and control groups (Figure 1).

Figure 1

Flow Diagram

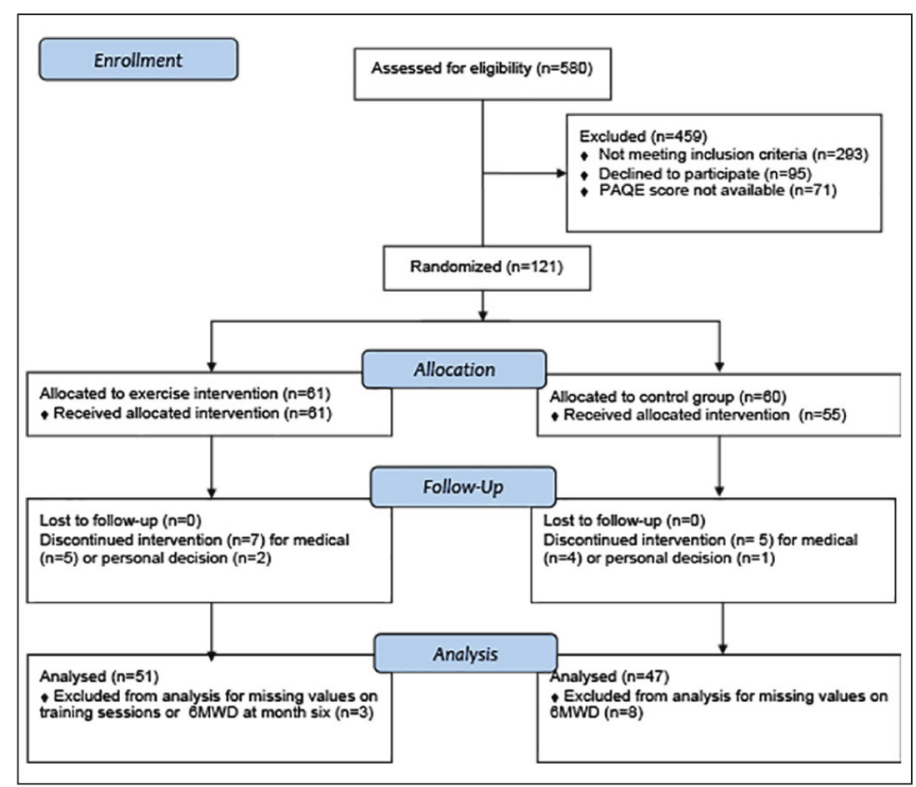

PAQE: Physical Activity Questionnaire for the Elderly

\section{Baseline data}

Characteristics of women in both groups were comparable, except for body weight and BMI which were lower in the exercisers (Table 1). At baseline, all exercisers and controls were under the 6MWD age-matched norm $(-23.1 \%$ and $-22.5 \%$ on average, respectively).

\section{Main outcome}

Over the 6-month follow-up, 6MWD increased more significantly in exercisers than in controls (mean increase of $41.5 \%$ vs $11 \%$, respectively; $\mathrm{p}<0.0001$ )(Table 2 ). All exercisers but one $(98.0 \%)$ improved their $6 \mathrm{MWD}$ over the 6-month intervention program vs $35(74.5 \%)$ in the control group $(\mathrm{p}=0.0006)$. After the 6-month program, 38 exercisers $(74.5 \%)$ had a $6 \mathrm{MWD}$ over the age-matched norm vs $5(10.6 \%)$ in the control group $(\mathrm{p}<0.0001)$.

\section{Secondary outcomes}

BMI and body composition (fat mass, lean mass) did not change over the 6-month follow-up in either group. Compared to baseline, daily physical activity increased in both groups $[+48.1 \%$ on average in 36 exercisers $(p=0.12)$ vs $+53 \%$ on average in 35 controls; $\mathrm{p}<0.001$ )], with a comparable magnitude $(\mathrm{p}=0.26)$. Exercisers with the highest tertile of 6MWD improvement $(>46 \%)$ were those with baseline lowest values of 6MWD $(\mathrm{p}=0.001)$ and grip strength $(\mathrm{p}=0.054)$, lowest mean heart rate recorded during the four first sessions ( $\mathrm{p}=0.004)$, and highest values of BMI $(p<0.01)$.

\section{Table 1}

Baseline characteristics of the randomized participants in the study $(n=98)$

\begin{tabular}{|c|c|c|}
\hline Baseline characteristics & $\begin{array}{l}\text { Exercisers } \\
\qquad(\mathrm{N}=\mathbf{5 1})\end{array}$ & $\begin{array}{l}\text { Controls } \\
(\mathrm{N}=47)\end{array}$ \\
\hline Age in years [mean (SD)] & $65.58(4.44)$ & $65.78(4.15)$ \\
\hline \multicolumn{3}{|l|}{ Last level of education reach attained $[\mathrm{n}(\%)]$} \\
\hline Single & $7(13.73)$ & $7(14.89)$ \\
\hline Married/PACS & $31(60.78)$ & $20(42.55)$ \\
\hline Divorced/Separate & $10(19.61)$ & $15(31.91)$ \\
\hline Widow & $3(5.88)$ & $5(10.64)$ \\
\hline \multicolumn{3}{|l|}{ Type of home [n (\%)] } \\
\hline In family & $34(66.67)$ & $23(48.94)$ \\
\hline Alone & $16(31.37)$ & $23(48.94)$ \\
\hline In community & $1(1.96)$ & $1(2.13)$ \\
\hline \multicolumn{3}{|l|}{ Tobacco $[\mathrm{n}(\%)]$} \\
\hline Never smoked & $38(74.51)$ & $32(68.09)$ \\
\hline Former smoker & $12(23.53)$ & $15(31.91)$ \\
\hline Current smoker & $1(1.96)$ & $0(0.00)$ \\
\hline Body weight in kg [mean (SD)] & $62.84( \pm 8.74)$ & $70.18( \pm 10.86)$ \\
\hline Body height in $\mathrm{cm}$ [mean (SD)] & $161.16( \pm 6.52)$ & $162.44( \pm 6.64)$ \\
\hline Body Mass Index $\left(\mathrm{Kg} / \mathrm{m}^{2}\right)[\mathrm{n}(\%)]$ & $24.25( \pm 3.46)$ & $26.64( \pm 4.22)$ \\
\hline [16.5 Kg/m²; $\left.18.5 \mathrm{Kg} / \mathrm{m}^{2}\right]$ & $2(3.92)$ & $0(0.00)$ \\
\hline$\left[18.5 \mathrm{Kg} / \mathrm{m}^{2} ; 25 \mathrm{Kg} / \mathrm{m}^{2}\right]$ & $31(60.78)$ & $17(36.17)$ \\
\hline $\left.125 \mathrm{Kg} / \mathrm{m}^{2} ; 30 \mathrm{Kg} / \mathrm{m}^{2}\right]$ & $14(27.45)$ & $23(48.94)$ \\
\hline $\left.130 \mathrm{Kg} / \mathrm{m}^{2} ; 35 \mathrm{Kg} / \mathrm{m}^{2}\right]$ & $4(7.84)$ & $7(14.89)$ \\
\hline Fat body mass in \% [mean (SD)] & $34.78( \pm 5.37)$ & $36.07( \pm 4.15)$ \\
\hline Lean body mass in \% [mean (SD)] & $62.20( \pm 5.05)$ & $61.28( \pm 3.88)$ \\
\hline $\begin{array}{l}\text { Physical Activity Questionnaire for the } \\
\text { Elderly [mean (SD)] }\end{array}$ & $6.75( \pm 3.69)$ & $6.95( \pm 3.69)$ \\
\hline Grip strength in Kpa [mean (SD)] & $21.25( \pm 5.61)$ & $22.43( \pm 5.73)$ \\
\hline 6-minute walking distance in $\mathrm{m}$ [mean (SD)] & $449.12( \pm 57.46)$ & $446.67( \pm 49.13)$ \\
\hline $\begin{array}{l}\text { Deviation below age-matched norms on } 6 \\
\text { MWD in } \% \text { [mean (SD)] }\end{array}$ & $23.09( \pm 9.02)$ & $22.50( \pm 7.06)$ \\
\hline
\end{tabular}

\section{Tolerance and attendance}

No adverse events (including falls) were reported as a result of the exercise intervention and attendance rate (sessions attended per absolute number of supervised sessions) was $92 \%$.

\section{Discussion}

The main result of this study is that sedentary women aged 60 years or older who exercise for 100 to 150 min per week for six months at a mean intensity of $75 \%$ maximum heart 
Table 2

Changes in 6-minute walking distance (6MWD), body composition, and grip strength over the 6-month program in exercisers and control participants

\begin{tabular}{|c|c|c|c|}
\hline & $\begin{array}{c}\text { Exercisers }(\mathbf{N}=51) \\
\text { Mean }(\mathrm{SD})\end{array}$ & $\begin{array}{c}\text { Controls }(\mathrm{N}=47) \\
\text { Mean }(\mathrm{SD}) \\
\end{array}$ & P value \\
\hline \multicolumn{4}{|l|}{ 6MWD (m) } \\
\hline Baseline & $449.12(57.46)$ & $446.67(49.13)$ & 0.54 \\
\hline 6 months & $624.59(68.28)$ & $492.85(70.34)$ & $<0.01 *$ \\
\hline$\%$ of variation & $41.54(25.93)$ & $11.00(15.82)$ & $<0.01 *$ \\
\hline \multicolumn{4}{|l|}{ Body weight (kg) } \\
\hline Baseline & $62.84(8.74)$ & $70.18(10.86)$ & $<0.01^{*}$ \\
\hline 6 months & $62.62(8.29)$ & $69.46(10.43)$ & $<0.01 *$ \\
\hline$\%$ of variation & $-0.25(2.79)$ & $-0.91(3.28)$ & 0.29 \\
\hline \multicolumn{4}{|l|}{ Body Mass Index $\left(\mathrm{kg} / \mathrm{m}^{2}\right)$} \\
\hline Baseline & $24.25(3.46)$ & $26.64(4.22)$ & $<0.01$ \\
\hline 6 months & $24.19(3.43)$ & $26.42(4.04)$ & $<0.01$ \\
\hline$\%$ of variation & $-0.19(2.96)$ & $-0.69(3.74)$ & 0.30 \\
\hline \multicolumn{4}{|l|}{$\%$ of Fat body mass (\%) } \\
\hline Baseline & $34.78(5.37)$ & $36.07(4.15)$ & 0.19 \\
\hline 6 months & $34.41(5.46)$ & $36.18(4.17)$ & 0.08 \\
\hline$\%$ of variation & $-1.01(5.61)$ & $0.24(4.40)$ & 0.23 \\
\hline \multicolumn{4}{|l|}{$\%$ of Lean body mass (\%) } \\
\hline Baseline & $62.20( \pm 5.05)$ & $61.28( \pm 3.88)$ & 0.36 \\
\hline 6 months & $62.58( \pm 5.16)$ & $61.21( \pm 3.94)$ & 0.22 \\
\hline$\%$ of variation & $0.66( \pm 3.33)$ & $-0.01( \pm 2.56)$ & 0.19 \\
\hline Physical Activity Questionnaire for the Elderly score & $(\mathrm{n}=36)$ & $(\mathrm{n}=35)$ & \\
\hline Baseline & $6.62( \pm 3.69)$ & $7.33( \pm 3.65)$ & 0.31 \\
\hline 6 months & $8.12( \pm 5.01)$ & $10.52( \pm 6.49)$ & 0.15 \\
\hline$\%$ of variation & $48.12( \pm 117.68)$ & $53.65( \pm 99.42)$ & 0.26 \\
\hline \multicolumn{4}{|l|}{ Grip strength (Kpa) } \\
\hline Baseline & $21.25( \pm 5.61)$ & $22.43( \pm 5.73)$ & 0.10 \\
\hline 6 months & $22.78( \pm 5.56)$ & $23.02( \pm 5.26)$ & 0.83 \\
\hline$\%$ of variation & $9.36( \pm 21.21)$ & $5.22( \pm 18.99)$ & 0.15 \\
\hline$* \mathrm{p}<0.0001$ & & & \\
\hline
\end{tabular}

rate improve their 6MWD by a mean of $41.5 \%$, without any significant adverse effects. Improvement is greater in those with higher BMI and lowest walking endurance at baseline.

Few randomized studies have assessed the effects of brisk walking programs on exercise tolerance in subjects aged 60 or older (20-26). In most studies, samples comprised less than 20 participants, daily physical activity before and after the program was not assessed, and walking program intensity, type (i.e. using treadmill or not), duration, and attrition rate varied strongly between studies, explaining at least in part why change in physical fitness in exercisers was variable in these studies $(0$ to $+14 \%)$. The strengths of the present randomized study are its relatively large sample size and long duration, continuous monitoring during supervised sessions of heart rate, intensity and duration of exercises, measurement of daily physical activities before and after the program, and the small drop-out rate.

In the present study, improvement in walking endurance was significantly higher in brisk walking exercisers than in controls ( $+45 \%$ vs $+11 \%$, respectively), whereas improvement in daily physical activities was comparable. This result supports the hypothesis that the brisk walking program itself is effective 
Table 3

Characteristics of exercisers in the upper tertile of 6MWD improvement $(\geq 46 \%)$ vs other exercisers

\begin{tabular}{|c|c|c|c|c|}
\hline & $\begin{array}{c}<46.34 \% \\
\mathrm{~N}=33 \\
\text { Mean (SD) }\end{array}$ & $\begin{array}{c}\geq 46.341 \\
\mathrm{~N}=18 \\
\text { Mean (SD) }\end{array}$ & $\begin{array}{c}\text { Crude Odds Ratio } \\
\text { [CI 95\%] }\end{array}$ & P-value \\
\hline \multicolumn{5}{|l|}{ Baseline characteristics } \\
\hline Body Mass Index $\left(\mathrm{Kg} / \mathrm{m}^{2}\right)(1)$ & $23.21(2.74)$ & $26.15(3.89)$ & $4.14[1.45 ; 11.79]$ & $* *$ \\
\hline Grip strength (Kpa) (2) & $22.42(5.89)$ & $19.11(4.46)$ & $1.95[0.99 ; 3.86]$ & 0.05 \\
\hline 6MWD (m) (3) & $476.26(35.97)$ & $399.36(56.79)$ & $8.98[2.46 ; 32.71]$ & $* * *$ \\
\hline \multicolumn{5}{|l|}{ Brisk walking program } \\
\hline Mean heart rate during the 4 first sessions (per min) (4) & $124.20(9.45)$ & $115.17(7.79)$ & $0.26[0.10 ; 0.65]$ & $* *$ \\
\hline Mean heart rate during supervised exercises (per min) (4) & $126.60(9.69)$ & $120.14(10.93)$ & $0.53[0.29 ; 0.98]$ & $*$ \\
\hline$\%$ maximum heart rate during supervised exercises (1) & $77.96(5.66)$ & $73.95(6.71)$ & $0.58[0.35 ; 0.96]$ & $*$ \\
\hline Total distance walked during supervised sessions $(\mathrm{km})(5)$ & $154.50(49.97)$ & $144.01(48.19)$ & $0.80[0.45 ; 1.45]$ & 0.46 \\
\hline Mean heart rate during the 4 last sessions (per min) (4) & $128.02(11.32)$ & $123.01( \pm 13.96)$ & $0.72[0.44 ; 1.16]$ & 0.17 \\
\hline
\end{tabular}

in improving exercise tolerance, independently of changes in habits induced by the program.

The significant increase in 6MWD $(+11 \%)$ found after 6-month follow-up in the control group, in whom physical activity was allowed freely, is possibly in part explained by the significant increase in physical activity (assessed by PAQE), that was comparable with that observed in exercisers. This finding tends to confirm that in women sufficiently concerned by their sedentary lifestyle to attend a public information meeting, education about physical activities and health benefits can induce a change in habits that can be associated with an increase in physical activities and walking endurance (27).

There is no gold standard method for assessing daily life physical activity. Questionnaires such as the PAQE reflects reported time periods engaged in specific behaviours whereas direct methods, including accelerometers, quantify acceleration resulting from bodily movement at a fixed point of the body. If both methods have advantages and limitations, the present results must be interpreted cautiously considering that physical activity is generally overestimated and sitting time generally underestimated by questionnaires when compared to physical activity trackers (28).

The high adherence rate during supervised sessions observed in exercisers $(92 \%)$ is comparable to that reported previously for brisk walking programs conducted in younger participants (11). While the absence of injury will have contributed to the high adherence rate in this study, the progressive training programme, tailored to each woman according to individual performance, and conducted by committed and experienced instructors to promote safety would also have been major factors as suggested earlier (29). Like in other studies, progression of the exercises, indicated by the number of meters walked for each session, was delivered in the intervention group to improve performance feedback and promote motivation (30; $31)$.

Supervised exercise sessions were delivered in small groups to promote health contacts and unsupervised sessions were self-monitored to promote active choice (30). Physical activity took place outdoors, in a city park, i.e. a natural and safe environment, easily accessible and very walkable and we allowed subjects choice in whether to perform the unsupervised walking in one or multiple bouts of exercise and replace supervised by unsupervised session during holiday time (31$33)$. These parameters have also possibly contributed to the high adherence to the program (10).

In the present study, as in some other randomized trials conducted in women of different age groups in whom caloric intake was allowed freely, the brisk walking program was not associated with a significant decrease in body weight, body fat or body lean mass $(20,21,26,34,35)$. It is possible that the increase in energy expended during the program may be of insufficient magnitude to promote weight loss in our sample of non-obese women or may have been counterbalanced by an increase in food intake in response to the increased energy expenditure.

Aerobic fitness has been shown previously to increase in a dose-response manner related to intensity, frequency, adherence, and duration of exercise $(6,7,10)$. In the present study, in which intensity, frequency, and duration were controlled and in which adherence was high, the main factors associated with walking endurance improvement were low baseline functional status and high BMI, suggesting that the most deconditioned participants are the ones with the greatest opportunity for walking endurance change. This result suggests also a possible ceiling effect for participants who were able to exercise close to $80 \%$ of their maximal heart rate at the 
beginning of the program. Taken together, our results supports the idea that brisk walking may be an appealing method to increase walking endurance in sedentary and physically deconditioned women, especially when slightly overweight.

Some limitations of the present study deserve attention. Duration and intensity of exercises during unsupervised sessions was not recorded in order to evaluate participants who were exercising to levels proposed by the FFEPGV for their brisk walking programs. Women entered into the study represent a healthy group, sufficiently health-conscious to attend public information meetings, and therefore may have been more motivated to change and more concerned by their sedentary lifestyle than the overall population of postmenopausal women (27). Although this sample bias may explain in part the high adherence of women to the program and therefore its optimal effect (10), we think it is realistic to consider that our data can be extended to the overall population of sedentary and physically deconditioned postmenopausal women ready to adhere to brisk walking programs and who are prepared to make the necessary changes. Exercise tolerance was measured using the 6MWD (distance covered by a subject who walks as quickly as she or he can in a period of $6 \mathrm{~min}$ ). Even if most participants do not achieve maximal exercise during the walking test, the 6MWD is strongly related to directlymeasured maximal oxygen consumption and is considered as a practical and ecological indicator of exercise tolerance or physical fitness in adult and older subjects $(18,19)$. In the present analysis, we did not include other markers of physical performance such as muscle strength and other factors such as housing environment $(36,37)$. The assessment of exercise tolerance via the $6 \mathrm{MW}$ test probably contributed to more participants completing the program when compared to studies using a maximal-graded treadmill test (29). A learning effect may have inflated the post-intervention 6MWD in both groups (38). As recommended, 3 walks have been performed at the beginning of the research study and 3 additional walks have been performed at the end of the 6-month intervention period without any intermediary measurements to minimize this effect (38).

To conclude, our findings lend support to current federal guidelines that endorse brisk walking as a moderateintensity exercise which is safe, achievable, and feasible for the majority of the population of women aged 60 or older. These results support the recommendation that deconditioned postmenopausal women, especially those with high BMI, should be encouraged to participate in brisk walking programs to improve their walking endurance in order to prevent chronic disease and maintain independence.

\section{Key points}

- This study aimed to examine if a 6-month brisk walking program can improve walking endurance in sedentary and physically deconditioned women aged 60 years or older.

- Three sessions of 50 minutes of brisk walking per week over
6 months improved exercise tolerance by $45 \%$ on average.

- The exercise tolerance improvement was the highest in women with the lowest physical performance and the highest $\mathrm{BMI}$ at baseline.

Conflicts of interest: None declared.

Funding: This work was supported by the French Ministry of Health [Projet Hospitalier de Recherche Clinique, UF-7606], the Montpellier University Hospital [Appel d'Offre Interne, UF 8189] and by a grant of the French federation of Physical Education and Voluntary Gymnastic (FFEPGV).

\section{References}

1. Sui X, LaMonte MJ, Laditka JN et al. Cardiorespiratory fitness and adiposity as mortality predictors in older adults. JAMA 2007; 298: 2507-16.

2. Paterson DH, Govindasamy D, Vidmar M, Cunningham DA, Koval JJ. Longitudinal study of determinants of dependence in an elderly population. J Am Geriatr Soc 2004; 52: 1632-8.

3. Department of Health, 2011. Physical Activity, Health Improvement and Protection Start Active. Stay Active: A report on physical activity from the four home countries' Chief Medical Officer. Department of Health, London UK.

4. 2016 Participation Report. The Physical Activity Council's annual study tracking sports, fitness, and recreation participation in the US. http://www. physicalactivitycouncil.com/pdfs/current.pdf

5. Murphy MH, Donnelly P, Shibli S, Foster C, Nevill AM. Physical activity, walking and leanness: an analysis of the Northern Ireland Sport and Physical Activity Survey (SAPAS). Prev Med 2012; 54: 140-4.

6. Thorogood A, Mottillo S, Shimony A et al. Isolated aerobic exercise and weight loss: a systematic review and meta-analysis of randomized controlled trials. Am J Med 2011; 124: 747-55.

7. Foulds HJ, Bredin SS, Charlesworth SA, Ivey AC, Warburton DE. Exercise volume and intensity: a dose-response relationship with health benefits. Eur J Appl Physiol 2014; 114: 1563-71.

8. Blumenthal JA, Emery CF, Madden DJ et al. Cardiovascular and behavioral effects of aerobic exercise in healthy older men and women. J Gerontol Med Sci 1989; 44: M147-57.

9. Chan L, Chin LM, Kennedy M, et al. Benefits of intensive treadmill exercise training on cardiorespiratory function and quality of life in patients with pulmonary hypertension. Chest 2013; 143: 333-43.

10. Garnier S, Joffroy S, Gaubert I et al. Is practice rate rather than exercise intensity more important in health benefits of moderately obese postmenopausal women? Ann Phys Rehabil Med 2015; 58: 119-25.

11. Murphy MH, Nevill AM, Murtagh EM, Holder RL. The effect of walking on fitness, fatness and resting blood pressure: a meta-analysis of randomised, controlled trials. Prev Med 2007; 44: 377-85.

12. Bernard PL, Tallon G, Ninot G, et al. Influence of a brisk walking program on isokinetic muscular capacities of knee in sedentary older women. Aging Clin Exp Res. 2016;28:1219-26.

13. Bernard PL, Blain H, Tallon G, et al. Influence of repeated effort induced by a 6-min walk test on postural response in older sedentary women. Aging Clin Exp Res. 2015; 27: 695-701.

14. Decker LM, Ramdani S, Tallon G, et al. Physical function decline and degradation of postural sway dynamics in asymptomatic sedentary postmenopausal women. J Nutr Health Aging. 2015;19: 348-55.

15. Bernard P, Ninot G, Bernard PL, et al. Effects of a six-month walking intervention on depression in inactive post-menopausal women: a randomized controlled trial. Aging Ment Health. 2015; 19: 485-92.

16. Wanner M, Probst-Hensch N, Kriemler S, et al. Validation of the long international physical activity questionnaire: Influence of age and language region. Prev Med Rep. 2016; 3: 250-6.

17. Troosters T, Gosselink R, Decramer M. Six-minute walking distance in healthy elderly subjects. Eur Respir J 1999; 14: 270-4.

18. Enright PL, McBurnie MA, Bittner V, Tracy RP, McNamara R, Arnold A, Newman AB; Cardiovascular Health Study The 6-min walk test: a quick measure of functional status in elderly adults. Chest. 2003; 123: 387-98.

19. American Thoracic Society Statement. Guidelines for the six-minute walk test. J Crit Care Med 2002; 166: 111-7.

20. Probart CK, Notelovitz M, Martin D, Khan FY, Fields C. The effect of moderate aerobic exercise on physical-fitness among women 70 years and older. Maturitas 1991; 14: 49-56.

21. Braith RW, Pollock ML, Lowenthal DT, Graves JE, Limacher MC. Moderate- and high-intensity exercise lowers blood pressure in normotensive subjects 60 to 79 years of age. Am J Cardiol 1994; 731124-8.

22. Ready AE, Drinkwater DT, Ducas J, et al. Walking program reduces elevated 
cholesterol in women postmenopause. Can J Cardiol 1995;11: 905-12.

23. Ready AE, Naimark B, Ducas J et al. Influence of walking volume on health benefits in women post-menopause. Med Sci Sports Exerc 1996; 28: 1097-105.

24. Hamdorf PA, Penhall RK. Walking with its training effects on the fitness and activity patterns of 79-91 year old females. Aust N Z J Med 1999; 29: 22-8.

25. Murtagh EM, Boreham CA, Nevill A, Hare LG, Murphy MH. The effects of 60 minutes of brisk walking per week, accumulated in two different patterns, on cardiovascular risk. Preventive Medicine $2005 ; 41: 92-7$.

26. Audette JF, Jin YS, Newcomer R, Stein L, Duncan G, Frontera WR. Tai Chi versus brisk walking in elderly women. Age Ageing 2006; 35: 388-93.

27. Harris T, Kerry SM, Victor CR, et al. A primary care nurse-delivered walking intervention in older adults: PACE (pedometer accelerometer consultation evaluation)-Lift cluster randomised controlled trial. PLoS Med 2015; 12: e1001783.

28. Sabia S, van Hees VT, Shipley MJ, Trenell MI, Hagger-Johnson G, et al. Association Between Questionnaire- and Accelerometer-Assessed Physical Activity: The Role of Sociodemographic Factors. Am J Epidemiol. 2014; 179: 781-790.

29. Ogilvie D, Foster CE, Rothnie H et al. Scottish Physical Activity Research Collaboration. Interventions to promote walking: systematic review. BMJ 2007; 334: 1204

30. Wulf G, Chiviacowsky S, Lewthwaite R. Normative feedback effects on learning a timing task. Res Q Exerc Sport. 2010; 81: 425-31.

31. Cress ME, Buchner DM, Prohaska T et al. Best practices for physical activity programs and behavior counseling in older adult populations. J Aging Phys Act 2005; 13: $61-74$.
32. Lacharité-Lemieux M, Brunelle JP, Dionne IJ. Adherence to exercise and affective responses: comparison between outdoor and indoor training. Menopause 2015; 22: 731-40.

33. Sellers CE, Grant PM, Ryan CG, O'Kane C, Raw K, Conn D. Take a walk in the park? A cross-over pilot trial comparing brisk walking in two different environments: park and urban. Prev Med 2012; 55: 438-43.

34. Irwin ML, Yasui Y, Ulrich CM et al. Effect of exercise on total and intra-abdominal body fat in postmenopausal women: a randomized controlled trial. JAMA 2003; 289: 323-30.

35. Tully MA, Cupples ME, Chan WS, McGlade K, Young IS. Brisk walking, fitness, and cardiovascular risk: a randomized controlled trial in primary care. Prev Med. 2005; 41: 622-8.

36. Bohannon RW. Association of Grip and Knee Extension Strength with Walking Speed of Older Women Receiving Home-care Physical Therapy. J Frailty Aging 2015; 4: 181-3.

37. Tanaka T, Tanaka K, Suyama K, Honda S, Senjyu H, Kozu R.A Comparison of Objective Physical Activity, Muscle Strength, and Depression among Communitydwelling Older Women Living in Sloped Versus Non-sloped Environments. J Nutr Health Aging. 2016; 20: 520-4.

38. Wu G, Sanderson B, Bittner V. The 6-minute walk test: how important is the learning effect? Am Heart J. 2003; 146: 129-33. 